\title{
LA VALIDEZ Y OPONIBILIDAD DE LOS PACTOS PARASOCIALES EN LAS COOPERATIVAS
}

\author{
Eduardo Miranda Ribera \\ Personal Investigador en Formación (FPI ${ }^{1}$ ) \\ Universitat Politècnica de València \\ http://orcid.org/0000-0003-3833-6645
}

\section{RESUMEN}

El planteamiento del presente trabajo surge debido a la actual tendencia de las cooperativas, concretamente las del sector agroalimentario, a someterse a procesos de integración con el objetivo de ser más competitivas y eficientes. En las sociedades de capital, para asegurar un adecuado funcionamiento y evitar situaciones de bloqueo de los órganos sociales, tradicionalmente, se ha optado por utilizar la figura de los pactos parasociales. Sin embargo, esta figura apenas presenta precedentes en las cooperativas. Por ello, en el presente trabajo se analizarán las principales características de los pactos parasociales, su validez y oponibilidad en las sociedades de capital, para posteriormente determinar si estos serían válidos entre los socios cooperativistas y oponibles a la sociedad cooperativa.

PALABRAS CLAVE: Pactos parasociales, cooperativas, validez, oponibilidad.

CLAVES ECONLIT / ECONLIT DESCRIPTORS: K200, K220, P130.

Cómo citar este artículo/How to cite this article: MIRANDA RIBERA, Eduardo: "La validez y oponibilidad de los pactos parasociales en las cooperativas", CIRIEC-España, Revista Jurídica de Economía Social y Cooperativa, n 38, 2021, pp. 261-289. D0I: 10.7203/ CIRIEC-JUR.38.20772

1. Ayudas para contratos predoctorales para la formación de doctores 2019 del Ministerio de Ciencia e Innovación, esta ayuda está contemplada en el Subprograma Estatal de Formación del Programa Estatal de Promoción del Talento y su Empleabilidad en I+D+i, en el marco de la convocatoria de ayudas del Plan Estatal de Investigación Científica y Técnica y de Innovación 2017-2020, publicada en BOE el día 8 de octubre de 2019 perteneciente al Programa Estatal de Promoción del Talento y su Empleabilidad en I+D+i, resuelta el 31 de julio 2020. 
(pp. 261-289)

\section{THE VALIDITY AND EFFECTIVENESS OF SHAREHOLDERS` AGREEMENTS IN COOPERATIVES}

\section{EXPANDED ABSTRACT}

Nowadays, the demands imposed by a globalized and competitive world require the adaptation of corporate relations. However, the rigidity of some laws and the rigorous qualification of official registries avoid the inclusion of clauses that promote greater corporate flexibility. Currently, a large number of companies use the shareholders' agreements to solve possible restrictions or situations which block the society. These types of agreements are those which are signed by all or some partners and, sometimes, also by the society. The aim of these agreements is to provide solutions to certain situations related with the functioning, organisation, or activity of a company.

However, given that the different types of agreements that can be incorporated into a shareholders' agreement, the specialised authors in the matter had distinguished between relationship agreements, attribution agreements and organizational agreements (this classification has also been recognised in different sentences as for example in the sentence of the "Audiencia" (High Court) of Barcelona of 11 th October 2019 [TOL 7.566.564] and the sentence of the "Audiencia" (High Court) of Murcia of $29^{\text {th }}$ November 2018]. The relationship agreements are characterised by containing agreements regarding the relations between the partners without affecting the company, such as, for example, the imposition of obligations to obtain shares under certain conditions. The attribution agreements are those which try to attribute advantages to the society as a result of the assumption of different obligations by the people who sign the shareholders' agreement, such as the configuration of financial obligations (for example the delivery of new contributions) or commercial obligations. The shareholders' agreements try to establish rules to improve the functioning and organisation of the society.

Nonetheless, we do not know any research about the usefulness and importance of shareholders' agreements in cooperatives, what is quite surprising, given that in cooperatives there are many situations which are similar to corporate companies ones. For this reason, shareholders' agreements could be useful in cooperatives.

In corporate companies shareholders' agreements are accepted, as long as they do not exceed the law, morality and the public order (article 1255 RD 24/07/1889, Civil Code). In particular, the specialized authors in this matter, accept the validity of shareholders' agreements while they do not violate the ius imperativum. Hence, shareholders' agreements that violate an im- 
perative Law will not be valid due to the fact that such agreement would violate the principle of legal certainty, by avoiding the correct identification of companies in the economic traffic.

Therefore, according to this interpretation, any agreement that aims to preserve the rights of the partners would be valid. Consequently, the validity of shareholders' agreements transcends beyond the violation of an imperative Law. For that reason, each agreement will have to be addressed and delimited whether it puts in danger any of the essential parts of the company. In spite of its validity, the agreement cannot be enforced to the company, however, when the shareholders' agreements are signed by all the partners, it could be enforced to the society. Despite the fact that making shareholders' agreement is expressly recognized in corporate companies, it cannot be enforced against the company (article 29 Royal Legislative Decree, $1 / 2010$, of $2^{\text {nd }}$ July, approving the consolidated text of the corporate enterprises Act).

The state cooperative Law and most of the regional legislation in cooperatives do not regulate this point related to shareholders' agreements, however, there are two regional laws, which recognise the possibility of cooperative members to make shareholders' agreements -in a similar way to corporate companies-(article 18.5 Law 9/2018, of October 30, on cooperative societies in Extremadura and art. 10.2 Law 11/2010, of November 4, of Cooperatives of Castilla-La Mancha).

Consequently, the shareholders' agreements must be admitted in absence of an express prohibition, based on the analogy iuris (article 1255 RD 24/07/1889, Civil Code). These agreements must be considered valid in cooperatives as long as they do not disobey a cooperative rule, principle, or value that tries to ensure, for example, the protection of third parties. In this way, the analysis of the validity of each specific shareholders' agreement will require a complete study of the rule, principle or cooperative value affected, in order to try to glimpse its scope and consequences.

As for its effectiveness, the specialized authors in the matter understands that, in some cases, shareholders' agreements can be enforced against the society when they are signed by all the partners. Nevertheless, this situation, does not seem an obstacle to the effectiveness of the shareholders' agreements, due to the fact that there are other legal instruments that ensure the fulfilment of all the responsibility agreed by all the partners. Therefore, shareholders' agreements are especially useful for regulating situations which cannot be included in the cooperative statutes.

In conclusion, in the light of the above, the shareholders' agreements between the members of a cooperative as for example, the intensity of the vote, the appointment of the members of the Governing Council or the configuration of a Governing Council when the appointment of 
a single director is mandatory, will be valid. However, despite its validity, this type of agreements will not always be effective against the cooperative. The effectiveness of the shareholders' agreements will be conditioned as they do not violate any principle or cooperative value, in particular those that try to ensure the mutuality and participation of the partners in the corporate governance of the cooperative. Therefore, given that the importance of cooperative principles and values to justify the effectiveness of shareholders' agreements against the cooperative, I consider it to be essential to defend an interpretation of the cooperative principles and values, in favour of the configuration of shareholders' agreements with the aim of promoting the creation of more competitive and efficient cooperatives.

KEYWORDS: Shareholders' agreements, cooperatives, validity, effectiveness. 


\section{SUMARIO}

I. Introducción: aproximación general a los pactos parasociales. II. La validez de los pactos parasociales. III. La oponibilidad de los pactos parasociales. IV. Conclusiones. Bibliografía.

\section{Introducción: aproximación general a los pactos parasociales}

No conocemos estudios doctrinales sobre la importancia que los pactos parasociales pueden adquirir en materia cooperativa, quizás porque subyace la idea de su incompatibilidad con los principios cooperativos. Sin embargo, las sociedades cooperativas -incluyendo no sólo las cooperativas de primer grado, sino también las cooperativas de segundo grado-, plantean entre los socios muchos problemas idénticos o similares a aquellos que tratan de solventarse en las sociedades de capital mediante pactos parasociales, como ocurre con los pactos para evitar situaciones de bloqueo en la toma de decisiones de los órganos sociales, que exigen la unanimidad o una mayoría reforzada en la toma de decisiones de inversión o con los pactos que permiten, por ejemplo, la salida de los socios con determinadas garantías. Muchas veces porque se trata de pactos que no tendrían cabida en las normas estatutarias o que, aun teniéndola, su incorporación lamentablemente puede plantear dificultades de acceso al registro al separarse de las reglas de la legislación -extensa y compleja- o de lo que resulta estándar; otras veces porque los socios pueden preferir mantener en secreto determinados pactos.

Con el objetivo de tratar de dar solución a estas posibles situaciones de bloqueo en las cooperativas, se propone, al igual que en las sociedades de capital, la opción de configurar un pacto parasocial. Esta figura, no definida legalmente, ha sido analizada por la doctrina mercantilista especializada en la materia que considera que este tipo de pactos hacen referencia a aquellos contratos firmados por todos o algunos socios y, en algunas ocasiones, también por la propia sociedad y tienen como objetivo aportar soluciones ante determinadas cuestiones relacionadas con el funcionamiento, toma de decisiones, organización o actividad de una sociedad ${ }^{2}$. En principio, este tipo de 
acuerdos no se integran en el "ordenamiento de la persona juridica a que se refieren, sino que permanecen en el recinto de las relaciones obligatorias de quienes lo suscriben"'. A pesar de esta desvinculación de la persona jurídica -manifestada en su condición de pacto autónomo o extraestatutario-, los acuerdos contemplados en los pactos parasociales suelen referirse a aspectos de la sociedad objeto de pacto. Por tanto, las personas que los suscriban asumirán determinadas obligaciones entre ellos, frente a terceros o frente a la sociedad ${ }^{4}$.

Ahora bien, dados los tipos de cláusulas que se pueden incorporar en un pacto parasocial, la doctrina mercantilista clásica ha distinguido entre pactos de relación, pactos de atribución y pactos de organización (esta clasificación también ha sido reconocida en la jurisprudencia como se observa ad. ex. en la SAP de Barcelona de 11 de octubre de 2019 [TOL 7.566.564] y SAP de Murcia de 29 de noviembre de 2018 [TOL 7.002.969] $)^{5}$. Los pactos de relación se caracterizan por contener acuerdos relativos a las relaciones entre los socios sin que afecten a la esfera de la sociedad, como, por ejemplo, la imposición de obligaciones de cesión o adquisición de participaciones sociales bajo determinadas condiciones ${ }^{6}$. Los pactos de atribución son aquellos "que se conciertan con el fin de procurar atribuir ventajas a la propia sociedad", como consecuencia de la asunción de diferentes obligaciones frente a la sociedad por parte de las personas que suscriban el pacto parasocial, como, por ejemplo, la configura-

en el mismo sentido, vid. FELIU REY, J.: "Las empresas de base tecnológica y los pactos parasociales", Revista de la Facultad de Derecho de la Universidad de Granada, no 15, 2012, pp. 136-137; y PASTOR I VICENT, M.: "Los pactos parasociales. Eficacia inter partes y frente a la sociedad", Revista jurídica de la Comunidad Valenciana, $\mathrm{n}^{\circ}$ 47, 2013, p. 31. Los pactos parasociales también podrán estar suscritos por personas que no sean socias (vid. MALDONADO ORTEGA, P.J.: "Pactos parasociales: Naturaleza y eficacia jurídica", Cuadernos de derecho y comercio, $\mathrm{n}^{\circ}$ Extra-1, 2017, p. 262; PÉREZ MORIONES, A.: "La necesaria revisión de la eficacia de los pactos parasociales omnilaterales o de todos los socios", Estudios de Deusto, vol. 61(2), 2013, pp. 268269. DOI: https://doi.org/10.18543/ed-61(2)-2013pp262-296).

3. Vid. PAZ-ARES RODRÍGUEZ, J.C.: "El enforcement...", p. 19. Véase igualmente, en el mismo sentido PASTOR I VICENT, M., op. cit., p. 31; y FELIU REY, J., op. cit., pp. 136-137.

4. Vid. PAZ-ARES RODRÍGUEZ, J.C.: "El enforcement...”, p. 19. Véase igualmente, en el mismo sentido PASTOR I VICENT, M., op. cit., p. 31; y PÉREZ MORIONES, A.: “La necesaria...”, pp. 268-269.

5. El tratadista italiano OPPO, G.: Contratti parasociali, Casa Editrice Dott. Franceso Vallardi, Milán, 1942, pp. 6-12; realizó una categorización de los tipos de pactos, que fue introducida en nuestra doctrina por el profesor PAZ-ARES RODRÍGUEZ, J.C.: "El enforcement...", p. 19; y seguida, entre otros, por GALACHO ABOLAFIO, A.F.: "Derechos de socios procedentes de pactos parasociales y su oponibilidad frente a la sociedad de capital”. En: Derecho de sociedades: los derechos del socio (dirs. GONZÁLEZ FERNÁNDEZ, M.B. \& COHEN BENCHERIT, A.), Tirant lo Blanch, València, 2020, pp. 85-88; y FELIU REY, J., op. cit., p. 138.

6. Vid. PAZ-ARES RODRÍGUEZ, J.C.: "El enforcement...”, p. 20. Véase igualmente, en el mismo sentido PASTOR I VICENT, M., op. cit., p. 32; FELIU REY, J., op. cit., p. 138; MALDONADO ORTEGA, P.J., op. cit., pp. 292-293; y GALACHO ABOLAFIO, A.F., op. cit., p. 86. 
ción de obligaciones de carácter financiero (como la entrega de nuevas aportaciones) o de carácter comercial (como la abstención de competir contra la propia sociedad) que los socios deben cumplir a favor de la sociedad ${ }^{7}$. Los pactos de organización tratan de establecer reglas para mejorar el funcionamiento y organización de la sociedad, como, por ejemplo, pactos relativos a la composición o funcionamiento del órgano de administración ${ }^{8}$.

Esta clasificación tradicional ha sido complementada por otros autores que entienden que los pactos parasociales pueden diferenciarse conforme a tres criterios más amplios: por un lado, desde un punto de vista subjetivo se diferencian aquellos pactos suscritos por todos los socios (también denominados pactos omnilaterales) y aquellos acuerdos suscritos por parte de algunos socios (esta clasificación también ha sido reconocida en la jurisprudencia como se observa ad. ex. en la STS de 20 de febrero de 2020 [TOL 7.790.005] y la SAP de Murcia de 29 de noviembre de 2018 [TOL 7.002.969]); por otro lado, desde un punto de vista objetivo los pactos parasociales podrían encuadrarse, conforme a la ya mencionada clasificación, en pactos de atribución, de relación y de organización; y, en último lugar, desde un punto de vista formal, los pactos parasociales pueden clasificarse por estar suscritos en documento público (escritura pública) o, por el contrario, en documento privado? . Una vez definida la figura del pacto parasocial y su tipología, interesa examinar la validez y la oponibilidad de este tipo de acuerdos en las sociedades cooperativas. Para ello, el presente trabajo analizará, en primer lugar, la validez de los pactos parasociales en las sociedades de capital, para, posteriormente, analizar su validez en las sociedades cooperativas y, en segundo lugar, se estudiará la oponibilidad de los pactos parasociales en las sociedades cooperativas partiendo de su análisis en las sociedades de capital.

7. Vid. PAZ-ARES RODRÍGUEZ, J.C.: "El enforcement...", p. 20: “El signo distintivo de esta categoría es que la incidencia del pacto sobre la esfera social es ventajosa”. Véase igualmente, en el mismo sentido PASTOR I VICENT, M., op. cit., p. 32; FELIU REY, J., op. cit., p. 138; MALDONADO ORTEGA, P.J., op. cit., pp. 293-294; y GALACHO ABOLAFIO, A.F., op. cit., p. 87. Los pactos de atribución también se denominan pactos "en beneficio de la sociedad".

8. Vid. PAZ-ARES RODRÍGUEZ, J.C.: "El enforcement...", p. 20. Véase igualmente, en el mismo sentido PASTOR I VICENT, M., op. cit., p. 32; FELIU REY, J., op. cit., p. 138; MALDONADO ORTEGA, P.J., op. cit., pp. 294-296; y GALACHO ABOLAFIO, A.F., op. cit., p. 88.

9. Vid. PASTOR I VICENT, M., op. cit., pp. 32-33. Otros autores como, FERNÁNDEZ DEL POZO, L.: "El 'enforcement' societario y registral de los pactos parasociales. La oponibilidad de lo pactado en protocolo familiar publicado", Revista de Derecho de Sociedades (RdS), no 29, 2007, pp. 143-144; entienden que existen 5 tipos de pactos: pre-societarios, parasociales o reservados, supra-estatutarios, infra-societarios y códigos de buenas prácticas. 
(pp. 261-289)

\section{La validez de los pactos parasociales}

La mejor doctrina considera que la cuestión relativa a la validez de este tipo de pactos no es una cuestión discreta, sino una cuestión de grado ${ }^{10}$. Conforme al principio general de libertad contractual, los socios de cualquier sociedad, con independencia de su tipología societaria, podrán establecer pactos siempre que no superen los límites de la autonomía de la voluntad, es decir, que no sean contrarios a la ley, la moral y al orden público (art. 1255 Código Civil $\left.{ }^{11}\right)^{12}$. Por tanto, con base en esta limitación, la doctrina mercantil clásica consideraba nulos los pactos que fueran contrarios a una norma imperativa o a los principios configuradores del tipo social ${ }^{13}$. Sin embargo, la doctrina actual, considera necesario matizar esta afirmación, al considerarla inapropia$\mathrm{da}$, excesiva y que no se "compadece con las expectativas normativas más generalizadas en la práctica" 14 .

En este sentido, siguiendo al profesor PAZ-ARES, que ha analizado detalladamente esta cuestión -en un tremendo y complicado ejercicio de intentar romper con el divorcio existente entre la teoría y la práctica jurídica-, para enjuiciar la validez de los pactos parasociales es necesario diferenciar entre dos tipos de normas imperativas:

10. Vid. PAZ-ARES RODRÍGUEZ, J.C.: "La validez de los pactos parasociales", Diario La Ley, no 7714, 2011, p. 1.

11. Real Decreto de 24 de julio de 1889 por el que se publica el Código Civil. Publicado en "Gaceta de Madrid" núm. 206, de 25/07/1889. BOE-A-1889-4763, en adelante Código Civil o CC.

12. Vid. PAZ-ARES RODRÍGUEZ, J.C.: “La validez...” p. 1. Asimismo, el Código de Comercio (Real Decreto de 22 de agosto de 1885 por el que se publica el Código de Comercio. Publico en "BOE" núm. 289, de 16/10/1885. BOE-A-1885-6627, en adelante Código de Comercio o CCom), alude a esta circunstancia, matizando que "los socios no podrán hacer pactos reservados, sino que todos deberán constar en la escritura social" (art. 119 CCom). Ello, no obstante, la doctrina y jurisprudencia han considerado que este precepto "nunca habia sido interpretado en el sentido de que fueran nulos dichos pactos, sino en el sentido indicado por el art. 117 CCom de que no se podian hacer valer frente a la sociedad". La validez de este tipo de acuerdos también ha sido reconocida por nuestra jurisprudencia como manifiestan, entre otros, PASTOR I VICENT, M., op. cit., pp. 29-74; FELIU REY, J., op. cit., p. 144. "La validez general de los pactos parasociales, hoy ya no se discute. Como regla de principio, los pactos parasociales son contratos válidos con carácter general”; MALDONADO ORTEGA, P.J., op. cit., p. 265.

13. Vid. GIRÓN TENA, J.: Derecho de Sociedades, Tomo I, Benzal, Madrid, 1976, p. 313; GARRIGUES, J.

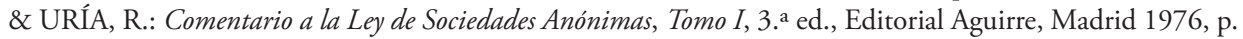
171; y más recientemente VICENT CHULIÀ, F.: "Licitud, eficacia y organización de los sindicatos de voto". En: Derecho mercantil de la Comunidad Económica Europea. Estudios en Homenaje a José Girón Tena, Civitas, Madrid, 1991, pp. 1229 y ss.

14. Vid. PAZ-ARES RODRÍGUEZ, J.C.: “La validez...”, p. 2. Véase igualmente, en el mismo sentido PASTOR I VICENT, M., op. cit., p.33; y FERNÁNDEZ DEL POZO, L.: "Acerca de la licitud de los pactos parasociales para el Consejo. La mala regulación de la cuestión en el proyectado Código Mercantil”, La Ley mercantil, no 3, 2014, pp. 21-23. 
el ius cogens (imperatividad tipológica), normativa reguladora sobre un determinado tipo de sociedad y, el ius imperativum (imperatividad sustantiva), normas de todos los tipos de sociedades que "las atraviesan en diagonal" y "establecen una ligazón entre inderogabilidad y normas y principios fundamentales del sistema jurídico" 15 . Por lo tanto, la validez de los pactos parasociales vendrá determinada por el ius imperativum (normativa que vela por los "valores centrales y fundamentales del derecho privado) y no por el ius cogens. Por ello, serán válidos aquellos pactos que afecten a los derechos individuales de los socios como, por ejemplo, el derecho de voto o información, por entenderse que estas normas se incluyen dentro del denominado ius cogens, por lo que, no representan un límite para los pactos parasociales ${ }^{16}$.

A partir de esta distinción puede entenderse que no serán válidos aquellos pactos que vulneren una norma imperativa que trate de proteger a los terceros, el interés de la sociedad o la salvaguarda de los elementos tipológicos esenciales de las normas sobre las sociedades, ya que ese pacto atentaría contra el principio de seguridad jurídica, al impedir una correcta identificación de las sociedades en el tráfico económico ${ }^{17}$. Igualmente, la validez de los pactos parasociales ha sido admitida por nuestra jurisprudencia, siempre y cuando se respeten las anteriores limitaciones (recientemente en STS de 20 de febrero de 2020 [TOL 7.790.005] ${ }^{18}$. De manera que, conforme a

15. Vid. PAZ-ARES RODRÍGUEZ, J.C.: "La validez...", p. 2. Véase igualmente, en el mismo sentido NIETO SÁNCHEZ, J.: "Los pactos parasociales: especial referencia al usufructo de acciones y participaciones sociales". En: Derecho mercantil. Estudios in memoriam del profesor Manuel Broseta Pont (dirs. OLAVARRÍA IGLESIA, J. \& MARTÍ MIRAVALLS, J.), Tirant lo Blanch, València, 2019, p. 304.

16. En este párrafo sigo a PAZ-ARES RODRÍGUEZ, J.C.: "La validez...”, pp. 2-4. Dentro del denominado ius cogens o imperatividad tipológica se incluirían "las normas especificas de la organización de la sociedad que no constituyen límite alguno para la autonomía privada, puesto que sólo afectan a las relaciones entre sus miembros, que pueden clasificarse en normas tecnocráticas, paternalistas y politicas". Por lo que respecta a las normas de tipo tecnocrático se hace referencia a aquellas que se "vinculan directamente a la estructura corporativa (personificación, colegialidad, estabilidad, etc.) con las que el legislador ha querido vertebrar la organización". Por su parte, las normas paternalistas, hacen referencia a aquellas situaciones donde se contrarían normas configuradas por "razones de protección de aquellas partes que se encuentran en una relación formal de supeditación respecto de otra". En última instancia, las normas de carácter político hacen referencia a las reglas que configuran los derechos individuales de los socios, como, por ejemplo, el derecho de información o el derecho de voto. Todas estas normas de carácter imperativo, al considerarse normas de ius cogens o imperatividad tipológica, no afectan a la "estructura pública y llamada a circular" de la sociedad y, por consiguiente, podrán ser objeto de un pacto parasocial.

17. Vid. PASTOR I VICENT, M., op. cit., p. 33.

18. Igualmente, véase en este sentido, entre otras, las SSTS de 25 de febrero de 2016 (TOL 5.658.004), de 6 de marzo de 2009 (TOL 1.466 .715 y 1.466.716), de 10 de diciembre de 2008 (TOL 1.413.638), de 18 de marzo de 2002 (TOL 4.975.369), de 10 de febrero de 1992 (TOL 1.654.698), de 26 de febrero de 1991 (TOL 1.728.201), de 24 de septiembre de 1987 (TOL 1.737.589), de 28 de septiembre de 1965 (TOL 4.308.157), y de 27 de septiembre de 1961 (TOL 4.337.541), y también, por citar alguna sentencia de Au- 
esta interpretación sería válido, por ejemplo, todo pacto que, a pesar de ser contrario a una norma imperativa, tenga como objetivo preservar los derechos de los socios que lo pactan. Por lo que, la validez de los pactos parasociales transciende más allá de la vulneración de una norma imperativa toda vez que habrá que atender a cada pacto concreto y delimitar si este pone el peligro alguno de los elementos tipológicos necesarios para poder identificar a la sociedad. Cuestión distinta es que, pese a su validez, el pacto no pueda oponerse a la sociedad, como en general así es salvo excepciones, como, por ejemplo, cuando el pacto haya sido suscrito por todos los socios.

La libertad para pactar entre los socios se reconoce expresamente en las sociedades de capital, al señalar la Ley que se pueden establecer pactos de carácter reservado entre los socios, sin que estos sean oponibles a la sociedad (art. 29 LSC $^{19}$ ). Sin embargo, en materia de sociedades cooperativas, la legislación estatal y la mayor parte de la legislación autonómica en materia de cooperativas no se pronuncia sobre este extremo. La legislación estatal cooperativa se asemeja a la Ley de Sociedades de Capital al establecer que en la escritura de constitución de la sociedad se deberán incluir todos los pactos que los socios fundadores quieran incorporar, siempre que no sean contrarios a los principios configuradores de las sociedades cooperativas (art. 28 LSC y art. 10 Ley de Cooperativas ${ }^{20}$ ). Sin embargo, la mayoría de las leyes en materia de

diencia, la SAP de Madrid de 29 de mayo de 2019 (TOL 7.366.560), la SAP de Murcia de 29 de noviembre de 2018 (TOL 7.002.969) y la SAP de Madrid de 2 de marzo de 2018 (TOL 6.627.099).

19. Real Decreto Legislativo 1/2010, de 2 de julio, por el que se aprueba el texto refundido de la Ley de Sociedades de Capital (en adelante LSC). Publicado en "BOE” núm. 161, de 03/07/2010. BOE-A-2010-10544.

20. Ley 27/1999, de 16 de julio, de Cooperativas. Publicada en "BOE” núm. 170, de 17/07/1999. BOE-A-1999-15681 (en adelante Ley de Cooperativas o LC). Sin embargo, esta disposición no se configura en todas las Leyes autonómicas en materia de cooperativas, solamente Asturias (Ley del Principado de Asturias 4/2010, de 29 de junio, de Cooperativas. Publicada en "BOE" núm. 232, de 24 de septiembre de 2010. BOE-A-2010-14628, en adelante LCAst) en su artículo 13 LCAst, País Vasco (Ley 11/2019, de 20 de diciembre, de Cooperativas de Euskadi. Publicado en "BOE" núm. 14 de 16/01/2020. BOE-A-2020-615, en adelante LCEusk) en su artículo 12 LCEusk y La Rioja (Ley 4/2001, de 2 de julio, de Cooperativas de La Rioja. Publicada en "BOE" núm. 172, de 19 de julio de 2001. BOE-A-2001-13944, en adelante LCRio) en su artículo 14.i) LCRio. El resto de las comunidades Autónomas: Castilla y León (Ley 4/2002, de 11 de abril, de Cooperativas de la Comunidad de Castilla y León. Publicada en "BOCL” núm. 79, de 26/04/2002. BOE-A-2002-9331, en adelante LCCyL), Cataluña (Ley 12/2015, de 9 de julio, de cooperativas. Publicada en "DOGC" núm. 6914, de 16/07/2015. BOE-A-2015-9140, en adelante LCCat), Comunidad de Madrid (Ley 4/1999, de 30 de marzo, de Cooperativas de la Comunidad de Madrid. Publicada en "BOCM" núm. 87, de 14/04/1999. BOE-A-1999-12334, en adelante LCMad), Extremadura (Ley 9/2018, de 30 de octubre, de sociedades cooperativas de Extremadura. Publicada en "DOE" núm. 213, de 02/11/2018. BOE-A-2018-16345, en adelante LCExt), Castilla-La Mancha (Ley 11/2010, de 4 de noviembre, de Cooperativas de Castilla-La Mancha. Publicada en "DOCM" núm. 221, de 16/11/2010. BOE-A-2011-2707, en adelante LCCLM), Murcia (Ley 8/2006, de 16 de noviembre, de Sociedades Cooperativas, de la Región de Murcia. Publicada en "BORM" núm. 282, de 07/12/2006. BOE-A-2007-9417, en adelante LCMur), Islas 
cooperativas -estatal y autonómicas- no hacen referencia a la posibilidad de realizar pactos reservados entre los socios, como sí establece la Ley de Sociedades de Capital. La excepción que rompe la anterior regla se encuentra en la Ley de Sociedades Cooperativas de Extremadura y en la Ley de Cooperativas de Castilla-La Mancha que establecen que "los pactos que se mantengan reservados entre los socios no serán oponibles a la sociedad cooperativa" (art. 18.5 LCExt y art. 10.2 LCCLM). Por tanto, se reconoce, al igual que en la Ley de Sociedades de Capital, la posibilidad de que los socios realicen pactos entre ellos al margen del contrato de la sociedad cooperativa. De manera que, ante la falta de una prohibición expresa en las demás leyes cooperativas, debe abogarse en favor de su admisión, con base en la analogía iuris (art. 4 CC) o en el principio general de la autonomía de la voluntad que permite los pactos de los socios siempre y cuando no sean contrarios a la ley, la moral y el orden público (art. 1255 CC).

Ahora bien, en sede de sociedades cooperativas, el mencionado límite del ius imperativum para determinar la validez de los pactos parasociales, vendrá delimitado, entre otros aspectos, por los principios y valores cooperativos ${ }^{21}$ que, entre otros,

Baleares (Ley 1/2003, de 20 de marzo, de Cooperativas de las Illes Balears. Publicada en "BOIB" núm. 42, de 29/03/2003. BOE-A-2003-7872, en adelante LCBal), Comunidad Valenciana (Decreto Legislativo 2/2015, de 15 de mayo, del Consell, por el que aprueba el texto refundido de la Ley de Cooperativas de la Comunitat Valenciana. Publicada en "DOCV" núm. 7529, de 20/03/2015. DOCV-r-2015-90416, en adelante LCCV), Navarra (Ley Foral 14/2006, de 11 de diciembre, de Cooperativas de Navarra. Publicada en "BOE" núm. 149, de 13/12/2006. BOE-A-2007-191, en adelante LCNav), Cantabria (Ley 6/2013, de 6 de noviembre, de Cooperativas de Cantabria. Publicada en "BOCT" núm. 221, de 18/11/2013. BOE-A-2013-12424, en adelante LCCan), Aragón (Decreto Legislativo 2/2014, de 29 de agosto, del Gobierno de Aragón, por el que se aprueba el texto refundido de la Ley de Cooperativas de Aragón. Publicada en "BOA" núm. 176, de 09/09/2014. BOA-d-2014-90375, en adelante LCAra), Andalucía (Ley 14/2011, de 23 de diciembre, de Sociedades Cooperativas Andaluzas. Publicada en "BOJA" núm. 225. BOE-A-2012-877, en adelante LCAnd) y Galicia (Ley 5/1998, de 18 de diciembre, de Cooperativas de Galicia. Publicada en "DOG” núm. 251. BOE-A-1999-6940, en adelante LCGal) no regulan expresamente esta premisa.

21. Vid. ALFONSO SÁNCHEZ, R.: "Los principios cooperativos como principios configuradores de la forma social cooperativa”, CIRIEC-España, Revista Jurídica de Economía Social y Cooperativa, no 27, 2015, pp. 58-59: "Los valores cooperativos son: autoayuda, autorresponsabilidad, democracia, igualdad, equidad, solidaridad, honestidad, transparencia, responsabilidad y vocación social; y los principios cooperativos son: afiliación voluntaria y abierta a toda persona capaz de utilizar sus servicios; gestión democrática por parte de los socios; participación económica de los socios en la distribución de los excedentes de ejercicio en proporción a sus operaciones con la cooperativa e interés limitado y voluntariamente fijado para el capital social; autonomía e independencia; educación, formación e información, cooperación entre cooperativas; e interés por la comunidad'. Véase igualmente, en el mismo sentido GADEA SOLER, E.: "Delimitación del concepto de cooperativa: de los principios cooperativos a la responsabilidad corporativa", CIRIEC-España, Revista Jurídica de Economía Social y Cooperativa, no 23, 2012, pp. 47-51; y MORILLAS JARILLO, M.J.: "Concepto y clases de cooperativas". En: Tratado de derecho de sociedades cooperativas, Tomo I (dir. PEINADO GRACIA, J.I. \& coord. VÁZQUEZ RUANO, T.), $2^{a}$ ed., Tirant lo Blanch, València, 2019, pp. 163-171. 
traten de velar por la protección de terceros, el interés social de la cooperativa o la protección de alguno de sus elementos del tipo social cuya alteración impediría su recognoscibilidad como tipo social específico. Los principios cooperativos han sido definidos como "auténticos pilares y normas fundamentales en orden a configurar la organización, funcionamiento y naturaleza cooperativa"22. A pesar de que no constituyen una norma jurídica, como consecuencia de su incorporación -positivización ${ }^{23}$ - en las diferentes legislaciones cooperativas, los principios cooperativos se consideran como "fuente material de la legislación cooperativa, influenciando de manera directa o indirecta en su contenido" y su interpretación ${ }^{24}$. De manera que los principios y valores cooperativos se erigen como un verdadero límite a la autonomía de la voluntad de las partes a la hora de realizar pactos sobre la cooperativa y evitar la configuración de "falsas cooperativas" 25 . Es más, la doctrina especializada en la materia afirma que los principios cooperativos actúan como verdaderos principios configuradores de la forma social cooperativa, por lo tanto, aquellas cooperativas que no los respeten perderán "la especial identidad de estas entidades, determinando su necesaria adscripción a las formas generales de sociedad [civil o colectiva, según el caso]"26. Otros autores entienden que, además, de los principios y valores cooperativos, aquello que diferencia a las cooperativas del resto de sociedades en el tráfico económico es la "mutualidady la participación de los socios en la gestión” ${ }^{27}$. Por lo que, en caso de realizar unos pactos

22. Vid. ALFONSO SÁNCHEZ, R., op. cit., pp. 58-59; CORBERÁ MARTÍNEZ, J.M.: "El principio de educación, formación e información como pilar básico del concepto de cooperativa”, CIRIEC-España, Revista Jurídica de Economía Social y Cooperativa, no 16, 2005, p. 112.

23. Vid. JULIÁ IGUAL, J.F. \& GALLEGO SEVILLA, L.P.: "Principios cooperativos y legislación de la sociedad cooperativa española: el camino hacia el fortalecimiento de su carácter empresarial", REVESCO. Revista de Estudios Cooperativos, no 70, 2000, p. 136; CORBERÁ MARTÍNEZ, J.M., op. cit., p. 115; VICENT CHULIÁ, F.: Introducción al Derecho mercantil, vol. I, 23a ed., Tirant lo Blanch, València, 2012, p. 1169.

24. Vid. ALFONSO SÁNCHEZ, R., op. cit., p. 60: "Ello ha permitido a nuestra doctrina y jurisprudencia defender, incluso, su carácter de auténticas normas jurídicas, directamente aplicables y a las que someter los estatutos $y$ los acuerdos sociales".

25. Loc. Cit:: "Cualquier regulación ajena a los mismos impediría calificar a las sociedades como cooperativas, por mucho que se autodefiniera como ley de cooperativas".

26. Ibid., p. 63.

27. Vid. SANTOS DOMÍNGUEZ, M.A.: "La relación de los principios cooperativos con el derecho", CIRIEC-España, Revista Jurídica de Economía Social y Cooperativa, no 27, 2015, pp. 115-119. Para un estudio pormenorizado de la mutualidad de las cooperativas me remito a PANIAGUA ZURERA, M.: Mutualidady lucro en la sociedad cooperativa, MacGraw-Hill Interamericana de España, Madrid, 1997; e ibid:: "La sociedad cooperativa. Las sociedades mutuas de seguros y las mutualidades de previsión social". En: Tratado de Derecho mercantil. Tomo 12: La sociedad cooperativa. Las sociedades mutuas y las entidades mutuales. Las sociedades labo- 
parasociales, se deberá evitar acordar cláusulas que "desvirtúen la función que ha de cumplir la forma social cooperativa" 28 , si bien nada ha de impedir una interpretación actualizada y procompetitiva de dichos principios. En definitiva, el análisis de la validez de cada pacto parasocial concreto, requerirá de un estudio minucioso de la norma, principio o valor cooperativo -en particular, aquellos que afecten a la mutualidad y la participación de los socios en la gestión- afectado, para tratar de vislumbrar su alcance y sus implicaciones respecto de la identificación de los rasgos configuradores de la sociedad cooperativa en el tráfico económico. Este análisis habrá de huir de aproximaciones que deben considerarse superadas hoy en día, así, por ejemplo, el principio democrático no puede impedir la atribución de los derechos de voto en atención a la actividad cooperativizada del socio o su inversión en la cooperativa, ni el pacto de varios socios comprometiéndose a votar en el mismo sentido en las Asamblea General (sindicatos de voto) ${ }^{29}$.

La alteración de la regla de la proporcionalidad del voto puede verse afectada por pactos entre socios que tengan como objetivo solventar una hipotética situación de bloqueo de la sociedad, sin existir un standard o prototipo de sociedad para los que estén configurados. Por ejemplo, en el caso de una cooperativa de segundo grado -a la que se le aplique la normativa estatal en materia de cooperativas-, donde concurran únicamente dos socios, los acuerdos deberán adoptarse por unanimidad de los votos $(\text { art. 26.6 LC })^{30}$, lo que, en ocasiones, puede evocar a una situación de bloqueo de

rales. La sociedad de garantía reciproca (dirs. OLIVENCIA, M., FERNÁNDEZ NOVOA, C. \& JIMÉNEZ DE PARGA, R.), Vol. 1, Marcial Pons, Ediciones Jurídicas y Sociales, Madrid, 2005.

28. Vid. ALFONSO SÁNCHEZ, R., op. cit., p. 63.

29. Para un estudio detallado sobre los sindicatos de voto me remito a PÉREZ MORIONES, A.: Los sindicatos de voto para la Junta General de Sociedad Anónima, Tirant lo Blanch, València, 1996; y VICENT CHULIÀ, F.: "Licitud...", pp. 1229 y ss.

30. Vid. MELIÁ MARTí, E., JULIÁ IGUAL, J.F., PALAU RAMÍREZ, F. \& MIRANDA RIBERA, E.: "Sistemas de gobierno y nuevas formas de organización. Las cooperativas de segundo grado de nueva generación. El caso de la OPFH RIBERCAMP, Coop. V.”. En: Cooperativismo agroalimentario y las OPFH (dirs. COlOM GORGUES, A. \& FLORENSA GUIU, R.M.), Aranzadi, Cizur Menor, 2021, pp. 142-146. Por ejemplo, ante la concurrencia de una cooperativa de segundo grado, la legislación estatal en materia de cooperativas establece que, "salvo en el caso de sociedades conjuntas de estructura paritaria, ningún socio de estas cooperativas podrá tener más del 30 por 100 del capital social de la misma" (art. 77 LC). En la Comunidad Valenciana, por ejemplo, el legislador autonómico regula que "en ningún caso una sola persona socia podrá ostentar más del $50 \%$ de los derechos de voto" y cuando uno de los socios de una cooperativa de segundo grado no posea la forma de cooperativa este porcentaje se reducirá al 40\% (art. 101 LCCV); por su parte, en el caso de una cooperativa de segundo grado que esté reconocida como una organización de productores de frutas y hortalizas $(\mathrm{OPFH})$, cada entidad socia deberá respetar el límite consistente en que el porcentaje máximo de derechos de voto y de aportaciones sociales de un socio "será inferior al 50\% del total de los derechos de voto y al 50\% de las acciones o capital' (art. 17 Real Decreto 532/2017, de 26 de mayo, por el que se regulan 
los órganos sociales. Estas situaciones de bloqueo podrán darse igualmente en cooperativas de primer grado cuya estructura societaria esté configurada de forma que puedan generarse situaciones de empate o que impidan la adopción de acuerdos que exigen una mayoría cualificada (ad. ex. art. 28 LC) ${ }^{31}$. Ahora bien, bajo determinadas circunstancias el legislador contempla la posibilidad de establecer un voto plural ponderado - en algunas cooperativas de primer grado y segundo grado- que, entre otras, podrá determinarse en función de la actividad cooperativizada de cada socio, siempre y cuando se respete el límite consistente en que ningún socio podrá ostentar un tercio de los votos totales de una cooperativa de primer grado y, en las cooperativas de segundo grado, el mencionado límite de $1 / 3$ se mantendrá, salvo cuando la cooperativa esté integrada por tres socios, por lo que, en ese caso el límite se elevará al $40 \%$ de los votos totales, y, en caso de estar integrada por dos socios, el límite se elevará al 50\% exigiéndose, en consecuencia, la unanimidad de los votos para adoptar un acuerdo (véase, por ejemplo, art. 26.2-7 LC, art. 52.2 LCAst, art. 42.2 LCIBal, art. 37.6 LCCan, art. 130 LCGal, art. 41.5 LCLRio, art. 44.6 LCMu) ${ }^{32}$.

el reconocimiento y el funcionamiento de las organizaciones de productores del sector de frutas y hortalizas -adelante LOPFH-).

31. Id.; FAJARDO GARCÍA, I.G.: "Los principios del derecho cooperativo europeo. El proyecto PECOL del grupo de estudio en derecho cooperativo europeo (SGECOL)". En: Derecho mercantil. Estudios in memoriam del profesor Manuel Broseta Pont (dirs. OLAVARRÍA IGLESIA, J. \& MARTí MIRAVALLS, J.), Tirant lo Blanch, València, 2019, p. 417: "Las decisiones se deben tomar por mayoría simple de los votos emitidos, pero las decisiones fundamentales, requerirán de mayorias cualificadas que se adoptarán siempre conforme a la regla de un voto por miembro"; BAENA BAENA, P.J.: "Órganos sociales". En: Tratado de derecho de sociedades cooperativas, Tomo I (dir. PEINADO GRACIA, J.I. \& coord. VÁZQUEZ RUANO, T.), 2a ed., Tirant lo Blanch, València, 2019, pp. 516-518.

32. Vid. BAENA BAENA, P.J., op. cit., pp. 501-502. En este sentido resulta de interés ilustrar algunos ejemplos de leyes autonómicas que se manifiestan en este sentido de no reconocer un voto dirimente o de calidad en la Asamblea General como, por ejemplo, la Ley de cooperativas de Castilla-La Mancha en su artículo 49.8: "en ningún caso podrá reconocerse en la asamblea general el voto dirimente o de calidad". Resulta igualmente interesante exponer otros ejemplos de limitación del porcentaje del voto plural contemplados en otras leyes autonómicas como, por ejemplo, la ley de cooperativas andaluzas que establece en su artículo 31.2 que, "en ningún caso, una persona socia pueda disponer de más del cincuenta por ciento de los votos sociales o del setenta y cinco por ciento en el caso de que estén formadas únicamente por dos sociedades cooperativas". Por su parte, la Ley de cooperativas de Castilla-La Mancha establece en su artículo 49.4 que "en ningún caso un sólo socio podrá ostentar más de un tercio de los votos totales de la cooperativa de primer grado, salvo que la cooperativa sólo tenga tres socios. En el caso de las cooperativas de segundo o ulterior grado, el límite máximo del tercio de votos por socio se ampliará hasta el cuarenta y nueve por ciento de los votos totales en aquellas cooperativas con menos de cuatro socios y no se aplicará en las cooperativas de sólo dos socios". Asimismo, la Ley de cooperativas de la Comunidad de Madrid establece en su artículo 35 que "ningún socio podrá ostentar más de un tercio de los votos totales, ni el conjunto de los votos ponderados ser superior al total de votos igualitarios, salvo que los Estatutos modifiquen este último límite. El límite del tercio de votos se ampliará hasta el 49 por 100 de los votos totales en las cooperativas de segundo grado con menos de cuatro socios; este límite no se aplicará en las de dos socios". La Ley de cooperativas de 
Por tanto, los socios podrían establecer medidas que tengan por objeto el sentido y el valor de los votos para evitar posibles situaciones de bloqueo ${ }^{33}$. Igualmente, podrían ser objeto de pacto parasocial la configuración de diferentes cláusulas que exigieran una mayoría cualificada de $2 / 3$ para la aprobación de determinados acuerdos en sede de la Asamblea General. Evidentemente, la validez de este tipo de acuerdos permanecerá en la esfera inter partes de los firmantes; posteriormente, se analizará si serían oponibles frente la sociedad.

Los pactos parasociales pueden también ser útiles para velar por la mutualidad y la participación de los socios en la gestión de las cooperativas y, en particular, la designación de los miembros del Consejo Rector. Los miembros del Consejo Rector, en principio, serán socios de la cooperativa ${ }^{34}$, aunque también es habitual encontrar en la legislación cooperativa normas -sin estar exentas de polémica- que permiten la integración de externos no socios dentro del Consejo Rector, para ello, estas personas deberán ser expertos o personas cualificadas para el desempeño de sus funciones, pudiendo designarse como número máximo de consejeros no socios un tercio del total de los miembros del Consejo y éstos no podrán ostentar ni el cargo de presidente, ni el de vicepresidente del Consejo Rector (ad. ex. art. 34.2 LC, art. 38 LCAnd, art. 50 LCIBal, art. 45 LCCan $)^{35}$. El Consejo Rector deberá estar integrado como

Navarra reconoce en su artículo 81 la posibilidad de que en las cooperativas de segundo grado se configure un voto proporcional y "los votos de los socios que no sean sociedades cooperativas no podrán superar el 40 por 100 del total de los votos existentes en la sociedad, pudiendo los estatutos establecer un limite inferior".

33. Ad. ex., en materia de sociedades de capital sobre la admisión de los pactos de sindicación de acciones, véase, la STS de 5 de mayo de 2016 (TOL 5.718.242), donde se establece que "el pacto de sindicación de acciones es un acuerdo extrasocietario o parasocial generalmente no oponible a la sociedad (art. 7.1 LSA, actual art. 29.1 LSC), pero de eficacia vinculante para quienes lo suscriben. Por este acuerdo los sindicados se comprometen, entre sí o frente a terceros, a votar en la junta general en un determinado sentido, decidido por la mayoría del sindicato y mediante el ejercicio del voto por sí mismos o a través de un representante, también elegido por el sindicato. En suma, se trata de un contrato asociativo que tiene como finalidad poder influir en las decisiones que se adopten en el seno de la junta general de la sociedad emisora".

34. Vid. VÁZQUEZ RUANO, T.: "Progresiva aproximación del régimen del órgano de administración de las sociedades cooperativas a las sociedades de capital". En: Derecho de sociedades. Revisando el derecho de sociedades de capital (dirs. GONZÁLEZ FERNÁNDEZ, M.B. \& COHEN BENCHETRIT, A.), Tirant lo Blanch, València, 2018, pp. 985-986; SALELLES, J.R.: "El Consejo Rector de las cooperativas y los principios de buen gobierno". En: Estudios de Derecho mercantil. Liber amicorum profesor Dr. Francisco Vicent Chuliá (dirs. CUNATT EDO, V., MASSAGUER FUENTES, J., ALONSO ESPINOSA, F.J. \& GALLEGO SÁNCHEZ, E.), Tirant lo Blanch, València, 2013, p. 610; TATO PLAZA, A.: "Órganos sociales". En: Tratado de derecho de sociedades cooperativas, Tomo I (dir. PEINADO GRACIA, J.I. \& coord. VÁZQUEZ RUANO, T.), 2a ed., Tirant lo Blanch, València, 2019, p. 561.

35. Véase, en este sentido, FAJARDO GARCÍA, I.G., op. cit., pp. 418-420; TATO PLAZA, A., op. cit., pp. 562-563; VÁZQUEZ RUANO, T., op. cit., p. 987. En este sentido, son de ver algunas diferencias relativas al límite máximo de consejeros no socios contemplados en las diferentes leyes autonómicas en materia de 
mínimo por 3 consejeros y, en caso de que la cooperativa sea de 3 socios, se admite que este órgano colegiado esté compuesto por 2 consejeros (ad. ex. art. 33 LC, art. 38 LCAnd, art. 38 LCAra, art. 44 LCCan, art. 41 LCCyL, art. 66 LCCLM, art. 42 LCCVal) ${ }^{36}$.

Algunos ejemplos sobre la utilidad de los pactos parasociales para la designación de los miembros del Consejo Rector serían aquellos acuerdos, entre miembros de un mismo grupo, que establecieran quién sería su representante y, por consiguiente, se podría postular como candidato para ser miembro del Consejo -dado que la aprobación de los miembros del Consejo Rector se adoptará en la Asamblea General (ad. ex. art. 34 LC, art. 38 LCAnd, art. 38 LCAra, art. 69 LCAst, art. 50LCIBal, art. 45 LCCan, art. 42 LCCyL, art. 66 LCCLM, art. 56 LCCat)-; o se podrían configurar pactos donde concurrieran todos los socios y decidieran acordar cuantos consejeros puede proponer cada socio o grupos de socios de la cooperativa. Igualmente, en aquellas cooperativas donde el número de socios sea inferior a 10 personas, podrá designarse un administrador único en lugar de un Consejo Rector (ad. ex. art. 32 LC, art. 38 LCAra, art. 54 LCCyL) ${ }^{37}$; en este caso en que es posible la designación de un administrador único, podrá ser también objeto de pacto parasocial la configuración de un Consejo Rector. Estos acuerdos, al igual que los contemplados para la Asamblea General, entendemos que serán igualmente válidos entre las partes, sin embargo, deberá verificarse posteriormente si son oponibles frente a la cooperativa ${ }^{38}$.

cooperativas. Por ejemplo, Aragón, Cataluña y Castilla-La Mancha limitan el número máximo de consejeros no socios al 25\% del total de miembros del Consejo Rector (art. 35 LCAra, art. 55 LCCat y art. 66 LCCLM). Por su parte, Castilla y León, limita el número máximo de consejeros no socios al $20 \%$ del total de miembros del Consejo Rector (art. 42 LCCyL).

36. En este sentido, véanse las discrepancias existentes en las diferentes leyes autonómicas. Por ejemplo, Asturias, Madrid y Cataluña no solamente configura un número mínimo de miembros del Consejo Rector, sino que establece un número máximo de miembros en la cifra de 15 personas (art. 69 LCAst, art. 44 LCCat, art. 41 LCMad). Por su parte la normativa de islas Baleares configura el límite máximo en la cantidad de 11 miembros (art. 49 LCIBal). Asimismo, cuando la cooperativa ostente más de 3 socios, necesariamente se deberá designar un presidente, un vicepresidente y un secretario (ad. ex. art. 33 LC, art. 38 LCAnd, art. 49 LCIBal, art. 44 LCCan).

37. Vid. VÁZQUEZ RUANO, T., op. cit., pp. 985-988; TATO PLAZA, A., op. cit., pp. 558-559 y 587.

38. Ad. ex., en materia de sociedades de capital sobre la admisión de los pactos sobre el nombramiento de los miembros del Consejo de administración, véase, la STS de 17 de noviembre de 2020 (TOL 8.217.268), donde se establece que "“la eficacia del pacto parasocial, perfectamente lícito, no puede defenderse atacando la validez de los acuerdos sociales que resulten contradictorios con los mismos, sino que debe articularse tal defensa a través de una reclamación entre los contratantes basada en la vinculación negocial existente entre los firmantes del pacto, pues este no tiene efectos frente a la sociedad ni, por tanto, en un litigio de naturaleza societaria como es el de impugnación de acuerdos sociales. Es, por tanto, en las relaciones internas entre los socios donde deberá dilucidarse 
En sede del Consejo Rector, podría también plantearse la configuración de un pacto parasocial en aras de evitar situaciones de bloqueo a la hora de adoptar acuerdos. Sin embargo, ello no será necesario dado que el propio legislador otorga un voto dirimente al presidente del Consejo para desbloquear las hipotéticas situaciones de empate (ad. ex. art. 36.4 LC, art. 46 LCCVal, art. 39 LCAnd, art. 57 LCCat) ${ }^{39}$. Por lo tanto, carece de sentido configurar una cláusula de este tipo a no ser que se quiera otorgar a otro vocal o compartir entre dos o más consejeros ese voto dirimente. No obstante, dada la importancia de la figura del presidente del Consejo Rector, sí sería interesante incluir una cláusula en los pactos parasociales donde se designará quién será el presidente del Consejo Rector de la cooperativa que, evidentemente, deberá ser aquella persona -física o jurídica- que más actividad cooperativiza realice o más recursos aporte a la sociedad ${ }^{40}$. También en esta sede, al igual que en la Asamblea General, podrá ser objeto de un pacto parasocial la configuración de una mayoría reforzada de $2 / 3$ para la adopción de determinados acuerdos del Consejo Rector.

Sí, con independencia de los mecanismos anteriores, se produjese una paralización de la Asamblea General o del Consejo Rector de una cooperativa, podría pactarse, dentro de los pactos parasociales, la constitución de un arbitraje ad hoc, distinto del arbitraje Cooperativo regulado en la Ley de Cooperativas, que se regiría por las normas establecidas en la Ley 60/2003, de 23 de diciembre, de Arbitraje ${ }^{41}$, para desbloquear la sociedad. La importancia de configurar este tipo de arbitraje, distinto del arbitraje cooperativo, radica en la autonomía configuradora que la mencionada Ley de Arbitraje otorga a las partes que deciden someterse al mismo, permitiéndoles designar libremente diferentes árbitros, siempre que sean número impar, para que otorguen una solución al problema planteado. Esta figura del arbitraje ad hoc distinto del arbitraje cooperativo puede ser igualmente interesante como método de resolución de conflictos internos surgidos entre los socios de la cooperativa, o entre algún socio frente a la cooperativa. Por lo que, podría incluirse, dentro de los pactos parasociales, una cláusula de sometimiento a arbitraje ad hoc en caso de que algún socio quisiera resolver algún tipo de controversia contra la propia cooperativa o contra otro socio.

En definitiva, los pactos entre los socios de una cooperativa relativos a, por ejemplo, la intensidad del voto, la designación de los miembros del Consejo Rector, la configuración de un Consejo Rector cuando sea preceptiva la designación de un

si se ha producido una vulneración del "Pacto de Accionistas" y, de haberse producido, qué efectos deben anudarse a tal vulneración".

39. Vid. SALELLES CLIMENT, J.R., op. cit., p. 617.

40. Vid. MELIÁ MARTÍ, E. et al., op. cit., pp. 142-146.

41. Publicada en "BOE” núm. 309, de 26/12/2003. BOE-A-2003-23646. 
administrador único o la constitución de un arbitraje ad hoc para la resolución de conflictos, serán válidos entre los socios de la cooperativa que firmen el acuerdo parasocial. Cuestión distinta será su oponibilidad frente a la sociedad que será objeto de estudio a continuación.

\section{La oponibilidad de los pactos parasociales}

Si un pacto parasocial es válido, se convertirá automáticamente en "ley entre las partes” (art. 1091 CC) ${ }^{42}$. De manera que, cualquiera de las partes firmantes podrá hacer valer su derecho frente a aquellos que incumplan lo pactado con cualquier medio disponible en Derecho para la defensa de sus intereses (véase, en este sentido, ad ex. SAP de Barcelona de 11 de octubre de 2019 [TOL 7.566.564] y la SAP de Murcia de 29 de noviembre de 2018 [TOL 7.002.969]). La vinculación del pacto a una sociedad no puede utilizarse como argumento para menguar la facultad de los firmantes para proteger sus derechos. De manera que, cada firmante estará facultado a ejercitar "la acción de indemnización de daños y perjuicios; la acción de cumplimiento en forma especifica (ejecución forzosa); la acción de remoción; la acción de resolución; y ciertas medidas de autotutela que pueden arbitrarse en el ámbito de la autonomía privada para minimizar el riesgo de incumplimiento" 43.

Hasta aquí se ha analizado la validez de los pactos parasociales entre las partes, pero también interesa analizar su oponibilidad frente a la sociedad. Sobre esta cuestión, existen diferentes pronunciamientos tanto jurisprudenciales ${ }^{44}$ como doctrinales en materia de sociedades de capital; no obstante, como ya se ha comentado, en

42. Vid. PAZ-ARES RODRÍGUEZ, J.C.: "El enforcement...”, p. 21; PÉREZ MORIONES, A.: "Impugnación de acuerdos sociales y pactos omnilaterales (reflexiones a la luz de los últimos pronunciamientos de nuestros tribunales)". En: Estudios de Derecho mercantil. Liber amicorum profesor Dr. Francisco Vicent Chuliá (dirs. CUNATT EDO, V., MASSAGUER FUENTES, J., ALONSO ESPINOSA, F.J. \& GALLEGO SÁNCHEZ, E.), Tirant lo Blanch, València, 2013, p. 583; MALDONADO ORTEGA, P.J., op. cit., p. 288.

43. En este párrafo sigo a PAZ-ARES RODRÍGUEZ, J.C.: "El enforcement... ”, p. 21. Véase, igualmente, en el mismo sentido a: NIETO SÁNCHEZ, J., op. cit., p. 306; PÉREZ MORIONES, A.: "Impugnación...", p. 583; MALDONADO ORTEGA, P.J., op. cit., p. 288; PASTOR I VICENT, M., op. cit., pp. 37-43.

44. Podrían citarse, a modo de ejemplo, las SSTS de 20 de febrero de 2020 [TOL 7.790.005], de 25 de febrero de 2016 (TOL 5.658.004), de 6 de marzo de 2009 (TOL 1.466 .715 y 1.466.716), de 10 de diciembre de 2008 (TOL 1.413.638), de 18 de marzo de 2002 (TOL 4.975.369), de 10 de febrero de 1992 (TOL 1.654.698), de 26 de febrero de 1991 (TOL 1.728.201), de 24 de septiembre de 1987 (TOL 1.737.589), de 28 de septiembre de 1965 (TOL 4.308.157) y de 27 de septiembre de 1961 (TOL 4.337.541), y también, por citar alguna sentencia de Audiencia, la SAP de Madrid de 29 de mayo de 2019 (TOL 7.366.560), la SAP de Murcia de 29 de noviembre de 2018 (TOL 7.002.969) y la SAP de Madrid de 2 de marzo de 2018 (TOL 6.627.099). 
materia de cooperativas no disponemos de esta información. Por ello, se analizará la experiencia habida en las sociedades de capital, para, a continuación, analizar si cabe su extrapolación a las sociedades cooperativas. Los tratadistas y expertos en la materia que se han centrado en la cuestión de la oponibilidad de los pactos parasociales se han centrado en estudiar, en primer lugar, la regla de la inoponibilidad y, en segundo lugar, la ruptura del principio de inoponibilidad ${ }^{45}$.

La doctrina mercantilista especializada en la materia ha considerado que, en esta sede, al contrario de lo que sucede en materia de validez, prima el principio de inoponibilidad de los pactos parasociales. Por ello, este tipo de pactos, al encontrarse al margen de la sociedad, no se integrarán en el ordenamiento de la persona jurídica y, por consiguiente, solamente persistirán en la esfera de aquellas personas que los suscriben. De manera que, existe una barrera que separa el contrato de sociedad de los pactos parasociales, quedando, en consecuencia, la sociedad ajena a lo pactado en el acuerdo parasocial. Al no afectar al contrato de sociedad se evita que este tipo de pactos se extiendan a los órganos de la persona jurídica o incluso afecten a terceros interesados en la sociedad. Esto provoca que un acto societario que vulnere lo acordado en un acuerdo extraestatutario podría ser perfectamente válido y eficaz. Sin embargo, esta barrera que separa la sociedad del pacto parasocial, en ocasiones se quebranta y puede plantear discrepancias sobre la separación de los pactos parasociales respecto de la sociedad ${ }^{46}$.

Si retomamos la clasificación tradicional de los pactos parasociales -que los clasificaba en pactos de atribución, relación y organización-, cuando se esté ante un pacto de atribución, como, por ejemplo, la obligación de conceder un préstamo a la sociedad por parte de los firmantes del acuerdo parasocial, o un pacto de relación, se entiende que los socios firmantes del pacto parasocial pueden reclamar lo pactado conforme a lo acordado, produciéndose así una ruptura de esa barrera que separa a la sociedad del pacto parasocial. Cuestión distinta y más compleja de solventar resulta la relativa a la configuración de pactos de organización, especialmente cuando alguno de los firmantes del pacto parasocial impugna un acuerdo adoptado en sede de la sociedad, fundamentando como motivo de la impugnación la vulneración de lo acordado en el pacto parasocial. Ante esta situación, en principio, la doctrina abo-

45. En este párrafo sigo a PAZ-ARES RODRÍGUEZ, J.C.: “El enforcement...”, p. 30.

46. En este párrafo sigo a ibid., pp. 30-31. Véase, igualmente, en el mismo sentido a: PASTOR I VICENT, M., op. cit., p. 44; NOVAL PATO, J.: "Los pactos parasociales". En: Estudios de Derecho de sociedades. Colegio Notarial de Valencia (dirs. EMBID IRUJO, J.M. \& NIETO CAROL, U.), Tirant lo Blanch, València, 2019, p. 95; FELIU REY, J., op. cit., p. 137. 
ga por el mencionado principio de inoponibilidad, por lo que, la impugnación del acuerdo social con base en la vulneración de pacto será ineficaz ${ }^{47}$.

Ahora bien, es necesario matizar esta regla de la inoponibilidad del pacto frente a la sociedad, dado que la doctrina y la jurisprudencia consideran que, en algunos casos, los pactos parasociales sí serán oponibles a la sociedad y, por consiguiente, conforme al ejemplo anterior, sí procederá la impugnación del acuerdo ${ }^{48}$. El primero de los argumentos consiste en que, si a la reunión donde se adopta el pacto parasocial acuden todos los socios, ésta podría considerarse como una Junta Universal, por lo que no tendría sentido mantener la regla de inoponibilidad dado que todos los socios son partícipes de las decisiones adoptadas en el pacto -acuerdo social adoptado en sede de Junta Universal- y, por consiguiente, vincularía a la sociedad ${ }^{49}$. El segundo de los argumentos vendría delimitado por la doctrina del levantamiento del velo de la persona jurídica, donde se considera que los tribunales podrán introducirse en la sociedad y superar el velo de la persona jurídica, para evitar el daño causado por algún socio en perjuicio del interés del resto de los socios, como consecuencia de la vulneración de un pacto parasocial suscrito por todos los socios ${ }^{50}$. El tercero de los

47. En este párrafo sigo a PAZ-ARES RODRÍGUEZ, J.C.: "El enforcement...”, pp. 31-32.

48. Véanse, en este sentido, entre otras, las SSTS de 20 de febrero de 2020 [TOL 7.790.005], de 25 de febrero de 2016 (TOL 5.658.004), de 3 de noviembre de 2014 (TOL 4.550.745), de 6 de marzo de 2009 (TOL 1.466 .715 y 1.466 .716 ), de 10 de diciembre de 2008 (TOL 1.413.638), de 10 de febrero de 1992 (TOL 1.654.698) y de 24 de septiembre de 1987 (TOL 1.737.589). Asimismo, para un comentario sobre algunas de estas sentencias me remito a PAZ-ARES RODRÍGUEZ, J.C.: "El enforcement...", p. 33; PASTOR I VICENT, M., op. cit., p. 45; PÉREZ MORIONES, A.: "Una vez más sobre la eficacia de los pactos parasociales tras la STS de 25 de febrero de 2016", Aranzadi Civil-Mercantil. Revista Doctrinal, no 5, 2016, pp. 174-175.

49. En este sentido véanse, entre otras, las SSTS de 3 de noviembre de 2014 (TOL 4.550.745), de 6 de marzo de 2009 (TOL 1.466.715 y 1.466.716), de 18 de marzo de 2002 (TOL 4.975.369), de 10 de febrero de 1992 (TOL 1.654.698) y de 26 de febrero de 1991 (TOL 1.728.201), y también, por citar alguna sentencia de Audiencia, la SAP de Murcia de 29 de noviembre de 2018 [TOL 7.002.969]. Igualmente, para un comentario detallado sobre algunas de estas sentencias véanse PAZ-ARES RODRÍGUEZ, J.C.: "El enforcement...”, p. 33; PASTOR I VICENT, M., op. cit., p. 46; PÉREZ MORIONES, A.: “Una vez...”, p. 171; NOVAL PATO, J., op. cit., p. 96.

50. En este sentido véanse las SSTS de 3 de noviembre de 2014 (TOL 4.550.745) y de 24 de septiembre de 1987 (TOL 1.737.589) donde, entre otras, se establece que "en varias sentencias, y en conformidad con la mejor doctrina, esta Sala no ha vacilado en apartar el artificio de la Sociedad Anónima para decidir los casos según la realidad, y así, la sentencia de 5 de mayo de 1958 prescindió de haberse constituido una Sociedad Anónima para hacer prevalecer el principio ético de que "nadie puede desposeer a otro sin la voluntad del despojado y por su propia decisión, cualquiera que sea el medio aparentemente empleado", y la de 28 de mayo de 1984, sienta la tesis general de que en el conflicto entre seguridad jurídica y justicia, valores hoy consagrados en la Constitución (artículos 1.1 y 9.3), se ha decidido prudencialmente y según los casos y circunstancias, por aplicar por vía de equidad y acogimiento del principio de la buena fe (art. 7.1 del Código Civil), la práctica de penetrar en el "substratum", personal de las entidades o sociedades, a las que la ley confiere personalidad jurídica propia, con el fin de evitar que al socaire 
argumentos exige que la imposibilidad de hacer valer el pacto parasocial frente a la sociedad suponga un abuso de derecho en perjuicio del interés social ${ }^{51}$. Ante la concurrencia de este tipo de situaciones, se podrá invocar la oponibilidad del pacto frente a la sociedad para equilibrar la balanza y evitar un perjuicio o abuso del derecho por parte de alguno de los firmantes del pacto ${ }^{52}$. De manera que, la mera infracción de un pacto parasocial omnilateral no será suficiente para impugnar un acuerdo social que lo vulnere, sino que, además, será necesario justificar que ese acuerdo social que vulnera el pacto supone un abuso de derecho y es perjudicial para el interés social (recientemente en STS de 20 de febrero de 2020 [TOL 7.790.005]) $)^{53}$.

Siguiendo al profesor PAZ-ARES, la regla de la inoponibilidad "obedece al principio de relatividad de los contratos, pero esta relatividad ha de entenderse tanto en un sentido subjetivo como en un sentido objetivo". En primer lugar, conforme al principio

de esa ficción o forma legal (de respeto obligado, por supuesto) se puedan perjudicar ya intereses privados o públicos como camino del fraude (art. 6.4 del Código Civil) admitiéndose la posibilidad de que los jueces puedan penetrar (levantar el velo jurídico), en el interior de esas personas cuando sea preciso para evitar el abuso de esa independencia (artículo 7.2 del Código Civil) en daño ajeno o de "los derechos de los demás", (artículo 10 de la Constitución) o contra el interés de los socios, es decir, de un mal uso de su personalidad, de un "ejercicio antisocial", de su derecho (artículo 7.2 del Código Civil). (...) La sentencia de 27 de noviembre de 1985 consideró que el sujeto pasivo de la deuda reclamada era el demandado y no la Sociedad de que era único socio y ello con independencia de la apariencia jurídica creada con la constitución de tal colectivo. (...) La sentencia de 9 de julio de 1986 prescindió de la forma social, por "la particular composición de la Sociedad recurrente» (tres socios, componentes del Consejo de Administración)". Asimismo, para un comentario detallado de algunas de estas sentencias me remito a PAZ-ARES RODRÍGUEZ, J.C.: "El enforcement...”, p. 33; PASTOR I VICENT, M., op. cit., p. 46; PÉREZ MORIONES, A.: “Una vez...”, p. 171; NOVAL PATO, J., op. cit., p. 96.

51. Véanse en este sentido las SSTS de 25 de febrero de 2016 (TOL 5.658.004), de 3 de noviembre de 2014 (TOL 4.550.745), de 6 de marzo de 2009 (TOL 1.466 .715 y 1.466.716), de 10 de diciembre de 2008 (TOL 1.413.638) y de 10 de febrero de 1992 (TOL 1.654.698) y también, por citar alguna sentencia de Audiencia, la SAP de Murcia de 29 de noviembre de 2018 (TOL 7.002.969) y la SAP de Madrid de 2 de marzo de 2018 (TOL 6.627.099). Para un comentario pormenorizado de algunas de estas sentencias me remito a PAZ-ARES RODRÍGUEZ, J.C.: "El enforcement...”, pp. 34-35; PASTOR I VICENT, M., op. cit., p. 47; PÉREZ MORIONES, A.: “Una vez...”, pp. 171 y 175; PÉREZ MORIONES, A., "Impugnación...”, p. 584; BENÍTEZ GARCÍA, R.: "Cuestiones conflictivas sobre la vigencia y alcance de los pactos parasociales. Comentario a la SAP de Barcelona 229/2019, de 12 de febrero (JUR 2019/62839)", Revista Aranzadi de derecho patrimonial, no 49, 2019, p. 7; NOVAL PATO, J., op. cit., p. 97.

52. Véase en este sentido la ya mencionada STS de 25 de febrero de 2016 (TOL 5.658.004), así como la resolución de la antigua Dirección General de los Registro y del Notariado de 26 de octubre de 1989, caso Promociones Keops. Para un análisis de esta sentencia y de la mencionada resolución de la antigua Dirección General me remito a PAZ-ARES RODRÍGUEZ, J.C.: "El enforcement...", p. 35; PASTOR I VICENT, M., op. cit., p. 47; PÉREZ MORIONES, A.: “Una vez...”, p. 172.

53. Véanse, en este sentido, las SSTS de 25 de febrero de 2016 (TOL 5.658.004), de 3 de noviembre de 2014 (TOL 4.550.745), de 6 de marzo de 2009 (TOL 1.466 .715 y 1.466.716), de 10 de diciembre de 2008 (TOL 1.413.638), de 10 de febrero de 1992 (TOL 1.654.698) y de 24 de septiembre de 1987 (TOL 1.737.589). 
de relatividad, "lo pactado por unos no puede afectar a otros". Esta situación se corresponde con el principio de inoponibilidad de los pactos frente a la sociedad dado que la sociedad, al tener personalidad jurídica propia, queda al margen de lo pactado entre los socios, toda vez que no coinciden las personas que suscriben el contrato de sociedad con aquellas que firman el pacto parasocial. Ahora bien, cuando el pacto parasocial esté suscrito por todos los socios, se rompería el mencionado principio de relatividad subjetiva por cuanto las partes del contrato de sociedad y el pacto parasocial son las mismas. Sin embargo, la concurrencia de todos los socios en el pacto parasocial no será suficiente para truncar el principio de inoponibilidad -relatividad objetiva y subjetiva-. Cuando se alude a la relatividad objetiva se hace referencia a que "los compromisos asumidos bajo un determinado régimen juridico no pueden ser hechos efectivos más que bajo ese régimen”. Dicho de otro modo, no podrá invocarse la tutela societaria para proteger el incumplimiento de determinados acuerdos establecidos en el pacto parasocial -no podrá solicitarse la exclusión de un socio por incumplir lo acordado en el pacto- ${ }^{54}$.

Sin embargo, existen supuestos donde la tutela de los intereses en vía societaria es equivalente a la otorgada por la vía contractual, como, por ejemplo, cuando se produce la impugnación de un acuerdo adoptado en sede social ${ }^{55}$. Por tanto, cuando exista una concordancia entre los sujetos que suscriben el contrato de sociedad y el pacto parasocial, así como, una equivalencia de resultados entre "el derecho de obligaciones y el derecho de sociedades"-coincidencia subjetiva y objetiva-, se romperá la regla de la inoponibilidad, lo que supondrá la posibilidad de exigir lo acordado en el pacto parasocial, frente a la sociedad ${ }^{56}$. A pesar de todo ello, la falta de oponibilidad del

54. En este párrafo sigo a PAZ-ARES RODRÍGUEZ, J.C.: “El enforcement...”, pp. 36-37.

55. Sobre las cuestiones más relevantes relativas a la impugnación de acuerdos en las sociedades cooperativas me remito a BAENA BAENA, P.J., op. cit., pp. 530-556; SENENT VIDAL, M.J.: La impugnació dels acords socials a la cooperativa [Tesis doctoral, Universitat Jaume I], Universitat Jaume I. Servei de Comunicació i Publicacions, Castelló de la Plana, 2003. DOI: https://doi.org/10.6035/10301/2001/55799.

56. Vid. PAZ-ARES RODRÍGUEZ, J.C.: “El enforcement...”, p. 38: "En el fondo, la ruptura de la regla de la inoponibilidad societaria obedece a un principio de racionalidad fundamental de nuestro ordenamiento jurídico, esa racionalidad que subyace a la regla de la economía procesal o — para ser más precisos - a la regla dolo facit qui petit quod redditurus est. De acuerdo con este viejo principio formulado por Paulus, actúa antijurídicamente, en efecto, quien se escuda en una norma que le ampara provisionalmente para dilatar el cumplimiento de su compromiso. No puede pedirse hoy lo que ha de devolverse mañana. No puede mantenerse ahora lo que ha de desaparecer después. En el fondo, late una de las ideas fundamentales del sistema jurídico: la inadmisibilidad de la conducta contradictoria. (...) La inadmisibilidad de la conducta de quien se opone a satisfacer por vía societaria lo que tendrá que satisfacer más tarde por vía contractual se funda, asi pues, en la falta de un interés propio duradero. Los firmantes que han incumplido el pacto no pueden pretender mantener ahora la validez de un acuerdo (apelando a que no pueden impugnarse los acuerdos sociales por violación de un pacto parasocial) cuando mañana se verán obligados a aceptar su desaparición (como consecuencia de la acción contractual de remoción)"; PASTOR I VICENT, 
pacto parasocial a la sociedad no parece un obstáculo a su ejecutabilidad, pues existen instrumentos jurídicos, como, por ejemplo, las cláusulas penales, que aseguran el cumplimiento por los socios de las obligaciones pactadas y, por ende, su actuación en los órganos sociales conforme a lo pactado.

En sede de sociedades cooperativas, será de aplicación igualmente el principio de inoponibilidad y, por ende, podrá romperse siempre y cuando se cumplan los anteriores requisitos. Sin embargo, además de los requisitos exigidos en sede de sociedades de capital, también se deberá tener en consideración si existe alguna vulneración de los principios y valores cooperativos, en particular aquellos que velan por garantizar la mutualidad y la participación de los socios en la gestión de la cooperativa.

En caso de que se configurase un pacto donde se designarán los miembros del Consejo Rector, este será oponible frente a la cooperativa siempre y cuando se respeten los límites relativos al número de externos no socios y se garantice que el Consejo Rector está integrado por miembros que representen, de una manera directa o indirecta, a todos los grupos integrantes de la cooperativa, dado que los socios no solamente participan en la actividad cooperativizada, sino que, además, se integran en la estructura orgánica de la sociedad ${ }^{57}$. El estudio de este tipo de acuerdos deberá ser minucioso y detallado, por cuanto, puede suponer una vulneración del principio de control democrático que vela por garantizar que la composición del Consejo Rector sea diversa y esté representada por todos los colectivos o grupos integrantes de la cooperativa.

Por otro lado, difícilmente será oponible un pacto parasocial donde se configure un voto plural ponderado diferente a la actividad cooperativizada, dado que, para ello, el legislador exige que ésta circunstancia deberá estar contemplada con claridad en los Estatutos sociales y deberá respetar, en todo caso, los límites contemplados supra referentes a los porcentajes de voto máximos de cada socio ${ }^{58}$. Por tanto, podrá

M., op. cit., p. 45: "A nuestro modo de ver, en el fondo, lo decisivo para la ruptura de la regla de la inoponibilidad son las razones de economía procesal. Lo importante es que los resultados obtenidos ejercitando acciones civiles son los mismos que se obtendrian a través de los remedios propios del ordenamiento societario"; BENÍTEZ GARCÍA, R., op. cit., p. 7: "Cuando el pacto parasocial es omnilateral, esto es, cuando es firmado por todos y cada uno de los socios, como sucede en el caso de la Sentencia que comentamos, el interés social se identifica con el de los socios, de modo que, la infracción de un pacto parasocial suscrito por todos los socios constituye una infracción del deber de lealtad"; GALLEGO CÓRCOLES, A.: "Impugnación de acuerdos sociales por abuso de mayoría e infracción de pactos omnilaterales tras la Ley 31/2014, de 3 de diciembre". En: Derecho de sociedades. Revisando el derecho de sociedades de capital (dirs. GONZÁLEZ FERNÁNDEZ, M.B. \& COHEN BENCHETRIT, A.), Tirant lo Blanch, València, 2018, pp. 1442-1446.

57. Vid. VÁZQUEZ RUANO, T., op. cit., pp. 985-986; SALELLES CLIMENT, J.R., op. cit., p. 610; TATO PLAZA, A., op. cit., p. 561.

58. Vid. VÁZQUEZ RUANO, T., op. cit., pp. 985-986; SALELLES CLIMENT, J.R., op. cit., pp. 500-503. 
darse la circunstancia de que los socios pacten un voto plural ponderado que será válido entre ellos, sin embargo, si no se cumplen las exigencias contempladas en las legislación cooperativa -estatal y autonómica-, ese pacto no será oponible frente a la sociedad. Algo similar sucede con la configuración de mayorías reforzadas para la aprobación de determinados acuerdos en sede de la Asamblea General y del Consejo Rector, dado que su validez permanecerá entre las partes firmantes, sin embargo, no serán oponibles frente a la sociedad.

En última instancia, si se pactara un acuerdo de sometimiento a arbitraje ad hoc -conforme a la Ley de Arbitraje mencionada supra- para la resolución de conflictos entre los socios o entre los socios y la cooperativa, esta cláusula que entendemos que sería válida entre las partes, también consideramos que sería oponible frente a la cooperativa. Imaginemos, por ejemplo, una cooperativa integrada por dos socios que son incapaces de adoptar un acuerdo en sede de la Asamblea General. Evidentemente, la paralización prolongada de los órganos sociales puede, entre otras, provocar la disolución de la sociedad. Sin embargo, si la cooperativa dispusiera de unos pactos parasociales que configuraran un arbitraje ad hoc donde cada uno de los socios pudiera designar un miembro que actuara como árbitro y, además, se integrara como miembro del tribunal arbitral un tercero imparcial -previamente designado por acuerdo de las partes en el momento de la configuración del pacto parasocial-, podría llegarse a un entendimiento, dado que el tercero sería quién desempatara y votara de manera objetiva atendiendo a las circunstancias del caso concreto y en atención al buen desarrollo de los intereses de la cooperativa. En caso de que, tras la decisión del tribunal arbitral, alguna de las partes quedara disconforme con el resultado obtenido, ésta podrá, al amparo del principio cooperativo de adhesión voluntaria y abierta, abandonar la sociedad ${ }^{59}$. De esta manera, se entiende que no existiría ninguna vulneración de tipo legal ni tampoco de los principios y valores cooperativos -y más concretamente de la mutualidad y la participación de los socios en la gestión-, ya que los derechos de voto de los socios se mantienen proporcionales y la solución del arbitraje ad hoc surge como solución última para solventar el hipotético bloqueo. Por tanto, en mi opinión, este pacto sí sería oponible a la sociedad, siempre y cuando concurriera la relatividad subjetiva y objetiva anteriormente mencionada.

59. Vid. FAJARDO GARCÍA, I.G., op. cit., pp. 415-416; PAZ CANALEJO, N.: "Principios cooperativos y prácticas societarias de la cooperación”, REVESCO. Revista de Estudios Cooperativos, no 61, 1995, pp. 20-21; LASSALETTA GARCÍA, P.J.: "Tipos de socios y otras formas de participación social". En: Tratado de derecho de sociedades cooperativas, Tomo I (dir. PEINADO GRACIA, J.I. \& coord. VÁZQUEZ RUANO, T.), 2a ed., Tirant lo Blanch, València, 2019, pp. 311-314; VARGAS VASSEROT, C.: "El principio cooperativo de puertas abiertas (adhesión voluntaria y abierta). Tópico o realidad en la legislación y la práctica societaria)", CIRIEC-España, Revista Jurídica de Economía Social y Cooperativa, no 27, 2015, pp. 133-174. 


\section{Conclusiones}

A modo de conclusión y al hilo de lo mencionado en los párrafos anteriores, los pactos parasociales entre los socios de una cooperativa relativos a, por ejemplo, la intensidad del voto, la designación de los miembros del Consejo Rector, la configuración de un Consejo Rector cuando sea preceptiva la designación de un administrador único o la constitución de un arbitraje ad hoc para la resolución de conflictos, serán válidos entre los socios de la cooperativa que firmen dicho acuerdo parasocial. Sin embargo, pese a su validez, este tipo de pactos no siempre serán oponibles frente a la cooperativa. Para que los pactos parasociales puedan ser oponibles frente a la cooperativa, deberá cumplirse la mencionada relatividad subjetiva y objetiva y, adicionalmente, no deberá vulnerarse ningún principio ni valor cooperativo, en particular aquellos que velen por garantizar la mutualidad y la participación de los socios en la gestión de la cooperativa. Por todo ello, dada la importancia de los principios y valores cooperativos para justificar la oponibilidad de los pactos parasociales frente a la cooperativa, considero oportuno abogar por una interpretación de los principios y valores cooperativos más actualizada y procompetitiva, en favor de la configuración de pactos parasociales con el objetivo de fomentar la creación de cooperativas más competitivas y eficientes. 


\section{Bibliografía}

ALFONSO SÁNCHEZ, R.: "Los principios cooperativos como principios configuradores de la forma social cooperativa”, CIRIEC-España, Revista Jurídica de Economía Social y Cooperativa, no 27, 2015, pp. 49-86.

BAENA BAENA, P.J.: "Órganos sociales". En: Tratado de derecho de sociedades cooperativas, Tomo I (dir. PEINADO GRACIA, J.I. \& coord. VÁZQUEZ RUANO, T.), 2a ed., Tirant lo Blanch, València, 2019, pp. 482-556.

BENÍTEZ GARCÍA, R.: "Cuestiones conflictivas sobre la vigencia y alcance de los pactos parasociales. Comentario a la SAP de Barcelona 229/2019, de 12 de febrero (JUR 2019/62839)", Revista Aranzadi de derecho patrimonial, no 49, 2019.

CORBERÁ MARTÍNEZ, J.M.: "El principio de educación, formación e información como pilar básico del concepto de cooperativa”, CIRIEC-España, Revista Jurídica de Economía Social y Cooperativa, no 16, 2005, pp. 101-130.

FAJARDO GARCÍA, I.G.: "Los principios del derecho cooperativo europeo. El proyecto PECOL del grupo de estudio en derecho cooperativo europeo (SGECOL)". En: Derecho mercantil. Estudios in memoriam del profesor Manuel Broseta Pont (dirs. OLAVARRÍA IGLESIA, J. \& MARTÍ MIRAVALLS, J.), Tirant lo Blanch, València, 2019, pp. 411-436.

FELIU REY, J.: "Las empresas de base tecnológica y los pactos parasociales", Revista de la Facultad de Derecho de la Universidad de Granada, no 15, 2012, pp. 131-179.

FERNÁNDEZ DEL POZO, L.: "El 'enforcement' societario y registral de los pactos parasociales, la oponibilidad de lo pactado en protocolo familiar publicado", Revista de Derecho de Sociedades (RdS), no 29, 2007, pp. 139-183.

FERNÁNDEZ DEL POZO, L.: "Acerca de la licitud de los pactos parasociales para el Consejo. La mala regulación de la cuestión en el proyectado Código Mercantil”, La Ley mercantil, no 3, 2014, pp. 18-29.

GADEA SOLER, E.: "Delimitación del concepto de cooperativa: de los principios cooperativos a la responsabilidad corporativa", CIRIEC-España, Revista Jurídica de economía social y cooperativa, no 23, 2012, pp. 37-58.

GALACHO ABOLAFIO, A.F.: "Derechos de socios procedentes de pactos parasociales y su oponibilidad frente a la sociedad de capital". En: Derecho de sociedades: los derechos del socio (dirs. GONZÁLEZ FERNÁNDEZ, M.B. \& COHEN BENCHERIT, A.), Tirant lo Blanch, València, 2020, pp. 79-100. 
GALLEGO CÓRCOLES, A.: "Impugnación de acuerdos sociales por abuso de mayoría e infracción de pactos omnilaterales tras la Ley 31/2014, de 3 de diciembre". En: Derecho de sociedades. Revisando el derecho de sociedades de capital (dirs. GONZÁLEZ FERNÁNDEZ, M.B. \& COHEN BENCHETRIT, A.), Tirant lo Blanch, València, 2018, pp. 1427-1448.

GARRIGUES. J. \& URÍA, R.: Comentario a la Ley de sociedades Anónimas, Tomo I, 3a. ed., Editorial Aguirre, Madrid, 1976.

GIRÓN TENA, J.: Derecho de Sociedades, Tomo I, Benzal, Madrid, 1976.

JULIÁ IGUAL, J.F. \& GALLEGO SEVILLA, L.P.: "Principios cooperativos y legislación de la sociedad cooperativa española: el camino hacia el fortalecimiento de su carácter empresarial", REVESCO. Revista de Estudios Cooperativos, no 70, 2000, pp. 125-146.

LASSALETTA GARCÍA, P.J.: "Tipos de socios y otras formas de participación social". En: Tratado de derecho de cooperativas, Tomo I (dir. PEINADO GRACIA, J.I. \& coord. VÁZQUEZ RUANO, T.), 2a ed., Tirant lo Blanch, València, 2019, pp. 311-340.

MALDONADO ORTEGA, P.J.: "Pactos parasociales: Naturaleza y eficacia jurídica", Cuadernos de derecho y comercio, no Extra-1, 2017, pp. 257-296.

MELIÁ MARTÍ, E., JULIÁ IGUAL, J.F., PALAU RAMÍREZ, F. \& MIRANDA RIBERA, E.: "Sistemas de gobierno y nuevas formas de organización. Las cooperativas de segundo grado de nueva generación. El caso de la OPFH RIBERCAMP, Coop. V.”. En: Cooperativismo agroalimentario y las OPFH (dirs. COLOM GORGUES, A. \& FLORENSA GUIU, R.M.), Aranzadi, Cizur Menor, 2021, pp. 127-156.

MORILLAS JARILLO, M.J.: "Concepto y clases de cooperativas". En: Tratado de derecho de sociedades cooperativas, Tomo I (dir. PEINADO GRACIA, J.I. \& coord. VÁZQUEZ RUANO, T.), 2a ed., Tirant lo Blanch, València, 2019, pp. 145-188. NIETO SÁNCHEZ, J.: "Los pactos parasociales: especial referencia al usufructo de acciones y participaciones sociales". En: Derecho mercantil. Estudios in memoriam del profesor Manuel Broseta Pont (dirs. OLAVARRÍA IGLESIA, J. \& MARTÍ MIRAVALLS, J.), Tirant lo Blanch, València, 2019, pp. 299-328.

NOVAL PATO, J.: "Los pactos parasociales". En: Estudios de Derecho de sociedades. Colegio Notarial de Valencia (dirs. EMBID IRUJO, J.M. \& NIETO CAROL, U.), Tirant lo Blanch, València, 2019, pp. 93-124.

OPPO, G.: Contratti parasociali, Casa Editrice Dott. Franceso Vallardi, Milán, 1942. PANIAGUA ZURERA, M.: Mutualidad y lucro en la sociedad cooperativa, MacGraw-Hill Interamericana de España, Madrid, 1997. 
PANIAGUA ZURERA, M.: "La sociedad cooperativa. Las sociedades mutuas de seguros y las mutualidades de previsión social". En: Tratado de Derecho mercantil. T. 12: La sociedad cooperativa. Las sociedades mutuas y las entidades mutuales. Las sociedades laborales. La sociedad de garantía reciproca (dirs. OLIVENCIA, M., FERNÁNDEZ NOVOA, C. \& JIMÉNEZ DE PARGA, R.), Vol. 1, Marcial Pons, Ediciones Jurídicas y Sociales, Madrid, 2005.

PASTOR I VICENT, M.: "Los pactos parasociales. Eficacia inter partes y frente a la sociedad", Revista jurídica de la Comunidad Valenciana, no 47, 2013, pp. 29-74. PAZ CANALEJO, N.: "Principios cooperativos y prácticas societarias de la cooperación", REVESCO. Revista de Estudios Cooperativos, no 61, 1995, pp. 15-34.

PAZ-ARES RODRÍGUEZ, J.C.: "El enforcement de los Pactos Parasociales", Actualidad Jurídica Uría \& Menéndez. no 5, 2003, pp. 19-43.

PAZ-ARES RODRÍGUEZ, J.C.: "La validez de los pactos parasociales", Diario La Ley, no 7714, 2011.

PÉREZ MORIONES, A.: Los sindicatos de voto para la Junta General de Sociedad Anónima, Tirant lo Blanch, València, 1996.

PÉREZ MORIONES, A.: "Impugnación de acuerdos sociales y pactos omnilaterales (reflexiones a la luz de los últimos pronunciamientos de nuestros tribunales)". En: Estudios de Derecho mercantil. Liber amicorum profesor Dr. Francisco Vicent Chuliá (dirs. CUNAAT EDO, V., MASSAGUER FUENTES, J., ALONSO ESPINOSA, F.J. \& GALLEGO SÁNCHEZ, E.), Tirant lo Blanch, València, 2013, pp. 581598.

PÉREZ MORIONES, A.: "La necesaria revisión de la eficacia de los pactos parasociales omnilaterales o de todos los socios", Estudios de Deusto, vol. 61(2), 2013, pp. 261-296. DOI: https://doi.org/10.18543/ed-61(2)-2013pp262-296

PÉREZ MORIONES, A.: "Una vez más sobre la eficacia de los pactos parasociales tras la STS de 25 de febrero de 2016”, Aranzadi Civil-Mercantil. Revista Doctrinal, no 5, 2016, pp. 167-179.

SALELLES CLIMENT, J.R.: "El Consejo Rector de las cooperativas y los principios de buen gobierno". En: Estudios de Derecho mercantil. Liber amicorum profesor Dr. Francisco Vicent Chuliá (dirs. CUÑAT EDO, V., MASSAGUER FUENTES, J., ALONSO ESPINOSA, F.J. \& GALLEGO SÁNCHEZ, E.), Tirant lo Blanch, València, 2013, pp. 599-654.

SANTOS DOMÍNGUEZ, M.A.: "La relación de los principios cooperativos con el derecho", CIRIEC-España, Revista jurídica de economía social y cooperativa, no 27, 2015, pp. 87-132. 
SENENTVIDAL, M.J.: La impugnaciódelsacordssocials a la cooperativa [Tesis doctoral, Universitat Jaume I], Universitat Jaume I. Servei de Comunicació i Publicacions, Castelló de la Plana, 2003. DOI: https://doi.org/10.6035/10301/2001/55799

TATO PLAZA, A.: "Órganos sociales". En: Tratado de derecho de sociedades cooperativas, Tomo I (dir. PEINADO GRACIA, J.I. \& coord. VÁZQUEZ RUANO, T.), $2^{\text {a }}$ ed., Tirant lo Blanch, València, 2019, pp. 556-597.

VARGAS VASSEROT, C.: "El principio cooperativo de puertas abiertas (adhesión voluntaria y abierta). Tópico o realidad en la legislación y la práctica societaria”, CIRIEC-España, Revista Jurídica de Economía Social y Cooperativa, no 27, 2015, pp. 133-174.

VÁZQUEZ RUANO, T.: "Progresiva aproximación del régimen del órgano de administración de las sociedades cooperativas a las sociedades de capital". En: Derecho de sociedades. Revisando el derecho de sociedades de capital (dirs. GONZÁLEZ FERNÁNDEZ, M.B. \& COHEN BENCHETRIT, A.), Tirant lo Blanch, València, 2018, pp. 985-1017.

VICENT CHULIÁ, F.: "Licitud, eficacia y organización de los sindicatos de voto". En: Derecho Mercantil de la Comunidad Económica Europea. Estudios en Homenaje a José Girón Tena, Civitas, Madrid, 1991, pp. 1205-1252.

VICENT CHULIÁ, F.: Introducción al Derecho mercantil, vol. I, $23^{\mathrm{a}}$ ed., Tirant lo Blanch, València, 2012. 